\title{
La noción de cuerpo en Judith Butler: una estructura imaginada, producto del deseo
}

\author{
The notion of body in Judith Butler: an imagined \\ structure and a product of desire
}

\author{
MARÍA DE LOS ÁNGELES PADILLA LAVIIN*
}

\begin{abstract}
Resumen: El tema de la corporalidad en la producción filosófica y política de Judith Butler es altamente polémico por la peculiar postura butleriana de poner en tela de juicio cualquier realidad enraizada con tintes normativos. Nuestro texto busca dar pautas para entender la postura y el tratamiento que esta autora hace, tanto de la corporalidad como de las estructuras de poder que constituyen al sujeto, el cual sólo tiene como posibilidad el desafiarlas, el desestabilizarlas y volverlas a configurar para significarlas como lo que son: meros constructos provisionales. En este sentido, desde la óptica butleriana es inviable lograr políticas estables.
\end{abstract}

Palabras clave: Cuerpo, deseo, subversión, tabú, homosexualidad, heterosexualidad normativa.

\begin{abstract}
The corporality in the philosophical and political production of Judith Butler is highly controversial due to the peculiar Butlerian position to question any rooted reality with regulatory appearance. Our text seeks to provide guidelines to understand the position and treatment this author provides about corporality and power structures that constitute the subject, whose unique possibility is to challenge, destabilize and re-configure such structures to give them meaning as what they truly are: mere provisional constructs. In this sense, from the Butlerian perspective, it is unfeasible to achieve stable policies.
\end{abstract}

Keywords: Body, desire, subversion, taboo, homosexuality, normative heterosexuality.

La noción de cuerpo en Judith Butler es quizá una de las más difíciles y polémicas de todo su pensamiento. Como se sabe, para esta filósofa el género no es natural, por lo que no existe ninguna razón por la que deba haber una relación de continuidad entre el cuerpo y el género (Butler, 1999) pero ¿qué noción de corporalidad tiene Judith Butler? ¿a qué se refiere cuando habla de incorporación? ¿cuál es la argumentación que elabora para negar

Fecha de recepción: 23/06/2016. Fecha de aceptación: 17/07/2016.

* Universidad Panamericana. Campus México. Facultad de Filosofía. Augusto Rodin 498, México, Ciudad de México, 03920, México. Vicerrectora Académica. lpadilla@up.edu.mx. Líneas de investigación: 1) La ideología de género y los valores sociales; 2) La representación mediática de la mujer y los valores sociales. Publicaciones significativas: 1) Nicolás, M.T., Quintanilla, C., Padilla, M.A., Vargas, P.P. (2015). A woman of the 60's caught in a contemporary TV series: Claire Dunphy a housewife in a "Modern Family". Communication \& Social Change, 3(1), 19-47. doi:10.17583/csc.2015.1774 2) Padilla, M.A. (2010). On the incorporation of women to the labour market and its impact on private life. Hospitalidad ESDAI, 17, 97-130. ISSN: 16651839. 
la «verdad» que la mayoría de los cuerpos albergan sobre su sexo? No se pueden responder estas preguntas sin esbozar, al menos someramente, la noción de cuerpo y la crítica que Butler hace a algunos de los autores más influyentes en su pensamiento. Mencionaremos a tres: Julia Kristeva, Monique Witting y Michel Foucault, además de señalar la influencia de Sigmund Freud en su pensamiento.

Para Judith Butler, el planteamiento kristevano de una desestabilización subjetiva en la cual, tanto la identidad social como la formación del individuo implican un proceso de abyección dirigido, fundamentalmente, contra el cuerpo de la madre es una política corporal atractiva puesto que difiere de la propuesta de un lenguaje impuesto por la ley paterna (Kristeva, 1980, 30). Sin embargo, para Butler, el discurso sobre la cuestión maternal no es realmente una estrategia subversiva -como lo juzga Kristeva- sino una aceptación tácita de hegemonía de lo Simbólico (Butler, 1990, 105).

Judith Butler prefiere la concepción de Monique Wittig quien afirma que el cuerpo no es más que un producto del esquema heterosexual que lo conforma (Wittig, 2006, 70), así como que el género y el sexo son efectos del discurso hegemónico que busca imponer una unidad artificial ${ }^{1}$. No obstante, a Butler le parece que la teórica feminista francesa que propone destruir esa clase construida por los hombres que se llama "mujeres" (Wittig, 2006, 43), subestima el significado y la significación del lenguaje respecto a "la marca del género" y que es excesiva su propuesta de destruir a los hombres (Butler, 1990, 36).

Especialmente importante para comprender la noción de cuerpo en Butler es la concepción de Michel Foucault sobre el deseo, autor que es ampliamente comentado por la filósofa postestructuralista en El género en disputa, su obra más conocida y que es considerada por muchos como el referente insoslayable de la ideología de género. Michel Foucault mantiene una posición menos firme que la de Julia Kristeva respecto al cuerpo ya que, por un lado, afirma que "el cuerpo es la superficie grabada de los acontecimientos [...] un volumen en constante desintegración" (Foucault, 1978, 148), idea que se encuentra en muchos de sus escritos y que señala que el análisis de la genealogía se encuentra, por tanto, en la articulación del cuerpo y la historia, de tal forma que la labor de la genealogía se reduce a mostrar un cuerpo completamente grabado por la historia y a ésta como el elemento que lo destruye. Judith Butler comenta que, de alguna forma, para Michel Foucault, al igual que para Friedrich Nietzsche, el cuerpo es una especie de página en blanco, un medio en el que se inscriben los valores culturales. Sin embargo, para significar esa inscripción, el medio debe destruirse, debe ser transvalorado a un nuevo campo de valores sublimado. La figura de la historia es una herramienta más de escritura, tanto el cuerpo como el medio debe ser destruido y transfigurado para que emerja la cultura (Butler, 1990, 165).

1 La idea, en realidad, fue originalmente planteada por el filósofo francés, Michel Foucault: “[...] la noción de «sexo» permitió agrupar en una unidad artificial elementos anatómicos, funciones biológicas, conductas, sensaciones, placeres, y permitió el funcionamiento como principio causal de esa misma unidad ficticia; como principio causal, pero también como sentido omnipresente, secreto a descubrir en todas partes: el sexo, pues, pudo funcionar como significante único y como significado universal”. (Foucault, 2009, 187). 
Para Butler, la vida es un dominio de pura posibilidad, en el que las restricciones y prohibiciones provienen de un esquema hegemónico que debe ser resistido a través de la creación de nuevos significados culturales, de tal forma que el cuerpo es solamente una estructura imaginaria que surge como consecuencia del deseo, cuya estrategia es tal, en el sujeto deseante, que éste no tiene reparo en realizar una especie de transfiguración de su cuerpo, modificándolo para adaptarse al deseo del cuerpo deseado: queda así claro que para Butler el cuerpo no es una materia estable y definida, sino un constructo del discurso y de la ley (Butler, 2012).

En El género en disputa es evidente que Judith Butler concibe el sujeto de deseo como la consecuencia de la prohibición impuesta culturalmente por lo que el cuerpo se convierte en una especie de receptáculo de todos los deseos anhelados en su superficie que, por la prohibición de la ley, no han podido ser consumados, constituyendo así, la identidad de género o identidad sexual. De esta forma, para la filósofa postestructuralista -como para Hegel- el deseo resulta ser el elemento constitutivo del sujeto pero, para ella, lo deseado es lo prohibido: el sujeto se constituye como aquello que ha deseado y no se le ha permitido desear. Esto explica su postura respecto a la homosexualidad y al incesto, que puede extrapolarse a otras realidades prohibidas. Y así, se entiende que, para Butler, las identidades estables de género sean forzosamente melancólicas porque están fundamentadas -en su opinión- en la prohibición de su deseo primario quedando sin resolver su amor (su deseo) homosexual original:

La negación de la investidura homosexual (el deseo y el objetivo juntos), negación impuesta por el tabú social y al mismo tiempo apropiada por etapas del desarrollo, da origen a una estructura melancólica que efectivamente recluye ese objetivo y ese objeto dentro del espacio corporal, o «cripta», establecido mediante una negación constante. Si la negación heterosexual de la homosexualidad origina la melancolía y si ésta interviene mediante la incorporación, entonces el amor homosexual no reconocido se salvaguarda desarrollando una identidad de género definida como opuesta. En definitiva, la homosexualidad masculina no reconocida termina en una masculinidad intensificada o afianzada, la cual mantiene lo femenino como lo impensable e innombrable (Butler, 2001, 142).

Judith Butler mantendrá y reafirmará esta postura con el tiempo, llegando a aseverar que el ser humano es "un sujeto deseante que desea desear lo que le es negado como una forma de seguir deseando" (Butler, 1997, 79). De alguna forma la oposición que encuentra al deseo de su deseo le permiten continuar deseando, lo que explica el binomio indisociable entre el deseo y la represión ejercida por el poder o, si se prefiere, entre el deseo y la ley que prohibiéndolo, le permite permanecer .

La teoría de las identidades melancólicas de género y de la incorporación de nuestra autora están, por otra parte, apoyadas en dos trabajos de Freud que influyen de manera importante en el pensamiento butleriano. El primero de ellos se titula "Duelo y Melancolía" (1917) y en él, Freud asevera que el duelo es la estructura incipiente del ego, mediante la que se gestiona la pérdida de un objeto amado, a través de la incorporación de la identidad, o bien, de los atributos del otro, planteamiento que Butler retoma para desarrollar su teoría de las identidades. 
El segundo trabajo decisivo de Freud para entender la corporalidad en Judith Butler es "El Yo y el Ello" (1923) en el que desarrolla el papel del deseo primario por la madre, así como la introyección de la figura materna en el infante. La autora resalta la afirmación propuesta por Freud en relación al duelo: "el carácter del yo es un residuo de las cargas de objeto abandonadas y contiene la historia de tales elecciones de objeto" (Butler, 1999, 139). De esta forma, la filósofa postestructuralista señala que el tabú del incesto da inicio a la pérdida de un objeto amado para el yo, mismo que es restablecido de esa pérdida mediante la incorporación del objeto del deseo que le es negado; en el caso de una relación homosexual, la pérdida es doble porque debe renunciarse tanto al objeto amado como a la modalidad del deseo $^{2}$, por lo que se sufre una doble estrategia interiorizadora de la melancolía.

Para elaborar su teoría sobre las identidades de género melancólicas, Butler retoma las disposiciones freudianas innatas que inclinan hacia un padre o hacia la madre, pero asevera que dichas disposiciones son efectos de procesos de identificación hacia el padre, o hacia la madre, más que ser innatas o causas de identificación. Esto implica, sin lugar a dudas, que el deseo no es el primero en aparecer y, mientras Freud describe la formación del yo como una estructura melancólica producida por la renuncia al deseo de su padre/madre como una respuesta al tabú del incesto, Judith Butler considera que el tabú del incesto está precedido por el de la homosexualidad:

El tabú contra el incesto, y de manera implícita contra la homosexualidad, es un precepto represivo que implica un deseo original situado en la noción de «disposiciones», el cual padece la represión de una inclinación libidinal originalmente homosexual y genera el fenómeno desplazado del deseo heterosexual (Butler, 2007, 150).

Esta es una de las propuestas más atrevidas y discutidas del pensamiento butleriano y, en este sentido, la identidad de género aparece primariamente como la internalización de una prohibición, con la suficiente fuerza para ser formativa de la identidad. Es claro que, para ella, todas las identidades de género parten de un deseo homosexual que está prohibido por el aparato cultural. Partiendo de que la melancolía es la respuesta a una pérdida real o imaginaria, Butler afirma que la identidad de género heterosexual se forma sobre la base de la pérdida primaria por el objeto de deseo del mismo sexo, por lo que todas las identidades heterosexuales son melancólicas.

De esta forma, Judith Butler, afirma que la estilización del cuerpo, así como la producción - disposición- del deseo sexual es resultado del tabú contra la homosexualidad a través de un complejo mecanismo que se ilustra en el anexo y que es el siguiente:

1) Internalización o interiorización: el tabú de la homosexualidad (que precede al tabú del incesto) activa la respuesta melancólica que produce la identificación con el padre/madre del mismo sexo ${ }^{3}$ (Butler, 1990, 81).

2 En una relación heterosexual prohibida, la pérdida es simple puesto que la modalidad del deseo puede permanecer, sólo se renuncia al objeto concreto.

3 Butler hace referencia aquí, propiamente, a la introyección freudiana en la que el objeto perdido es colocado en el yo como una identificación. 


\section{Anexo - Esquemas de la identificación de género en Judith Butler ${ }^{4}$}

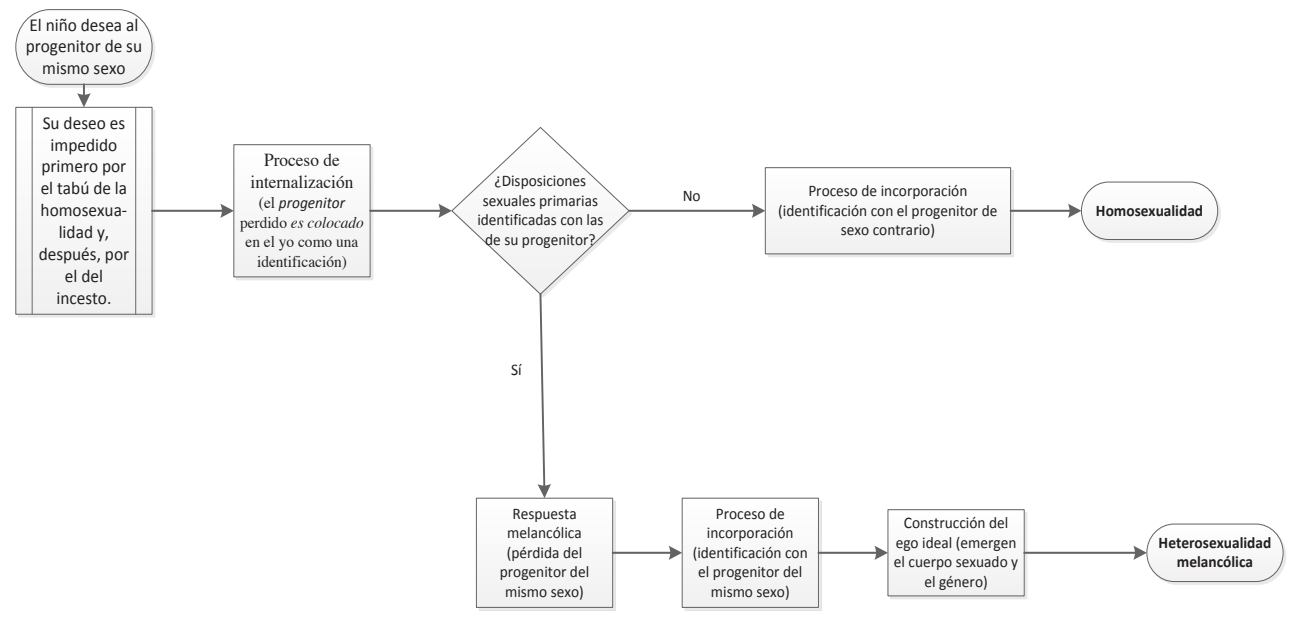

2) Incorporación de la identificación: una vez que la identificación melancólica ha tomado lugar, esta pérdida se encripta en el mismo cuerpo. El tabú del incesto da inicio a la pérdida del primer objeto amado para el yo, misma que es restablecida por la incorporación del objeto del deseo que le es negado (Butler, 1990, 75). La incorporación literaliza la pérdida dentro del cuerpo pero, de manera principal, en su superficie y aparece así la facticidad del cuerpo (Butler, 1990, 87). No es el "yo" freudiano el que asimila la pérdida de los objetos deseados, es el propio cuerpo, el que se convierte en el sepulcro de ellos.

3) La internalización y la incorporación explican que surja entonces el sexo, el cuerpo sexuado y el género como una verdad literal. Los deseos frustrados por los objetos perdidos, lejos de aparecer escondidos o enterrados, se conservan en la superficie del cuerpo y por lo tanto constituyen la identidad sexual y de género (Butler, 1990, 88-89). En esta tesitura, Butler afirma que ante una homosexualidad absolutamente negada aparecerá una masculinidad (o una feminidad) intensificada, a diferencia de lo que ocurre cuando ésta no se rechaza.

Ante un planteamiento de esta envergadura en el que el cuerpo, el sexo y el género no son más que resultado de determinaciones opresivas y restrictivas, las propuestas butlerianas son parte de lo que se puede llamar con propiedad una "política de subversión" y de "resignificación performativa" . Butler es consciente de la creciente fuerza política de los movimientos LGBT, en las últimas décadas, y sabe que su pensamiento expuesto en sus múltiples escritos es un soporte intelectual que los alienta a seguir buscando el reconocimiento social y el cambio en la legislación para que, en sus propias palabras, "esas vidas puedan ser habitables" (Butler, 1993, 3). Es necesario precisar que los textos de Judith Butler no contienen prescripciones precisas o explícitas sobre la práctica política o

4 Hemos elaborado este esquema para facilitar al lector el comprender la propuesta de identidad sexual que hace Butler (Butler, 1990, 81-82). 
modos específicos para desmontar la normatividad sobre el género. A lo más, se encuentra la propuesta de representar una parodia de manera repetitiva como elemento de significación para la deconstrucción de la identidad ${ }^{5}$, como una forma de resistir a la hegemonía de lo que ella considera una heterosexualidad obligatoria o normativa (Butler, 1990, 95).

Sin embargo, a pesar de esta postura política, pasiva en apariencia, hay una clara propuesta estratégica de insubordinación, permanente y activa, a la normatividad o al aparato cultural establecido que, en consonancia con su pensamiento, debe ser siempre cuestionado y desestabilizado, aun cuando se llegara a lo que ella tanto ansía: el reconocimiento de las minorías segregadas para llegar a tener una vida habitable.

Todo lo que hemos expuesto hace que el pensamiento butleriano constituya un desafío político, ciertamente perturbador e imposible de llevar a buen término, por su mismo planteamiento: sólo hay compromiso con la permanente desestabilización de la normatividad observada.

\section{Bibliografía}

Butler, Judith (1990): Gender Trouble: Feminism and the Subversion of Identity, Routledge, New York.

Butler, Judith (1993): Bodies that Matter: on the Discursive Limits of "Sex", Routledge, New York.

Butler, Judith (1997): The Psychic Life of Power: Theories of Subjection, Stanford University Press, New York.

Butler, Judith (2001): Mecanismos psíquicos del poder. Teorías sobre la sujeción, Cátedra, Madrid.

Butler, Judith (2007): El género en disputa: el feminismo y la subversión de la identidad, Paidós, Barcelona.

Butler, Judith (2012): Sujetos del deseo. Reflexiones hegelianas en la Francia del Siglo XX, Amorrortu, Buenos Aires.

Foucault, Michel (1978): "Nietzsche, la genealogía, la historia” en La microfísica del poder, La Piqueta, Madrid.

Foucault, Michel (2009): Historia de la Sexualidad. La Voluntad de Saber, Vol. I, Siglo XXI, México.

Freud, Sigmund (2007): "Duelo y melancolía" (1917 [1915]) en Obras Completas, tomo XIX (1914-1916), Amorrortu, Argentina.

Freud, Sigmund (2007): "El yo y el super-yo" en Obras Completas, tomo XIX (1923-1925), Amorrortu, Argentina.

Kristeva, Julia (1980): Desire in Language, a Semiotic Approach to Literature and Art, Columbia University Press, New York.

Wittig, Monique (2006): El pensamiento heterosexual y otros ensayos, Egales, Madrid.

5 Judith Butler considera que cualquier acción posible debe aceptar la dinámica del poder, que no puede ser retirado, ni rechazado, sino sólo replanteado (Butler, 1990, 158). En su planteamiento, si se pudiese prescindir del poder, ello significaría que el contrato heterosexual habría sido preservado a través de un conjunto de elecciones racionales, fruto de acciones de una voluntad deliberada. Como Butler niega el modelo clásico sobre la libertad, propone que el propósito normativo para las prácticas lésbico-gay partan de un replanteamiento subversivo y paródico del poder que socave la normatividad de una heterosexualidad obligatoria. 